\title{
Distribution of Cardiac Output in Fetal and Neonatal Lambs with Acute Respiratory Acidosis
}

\author{
ADAM A. ROSENBERG, ${ }^{(35)}$ RAYMOND C. KOEHLER, AND M. DOUGLAS JONES JR. \\ Departments of Pediatrics (Eudowood Neonatal Division), Gynecology and Obstetrics, and Anesthesiology and \\ Critical Care Medicine, The Johns Hopkins University School of Medicine, Baltimore, Maryland, USA
}

\begin{abstract}
Summary
The effects of changes in $\mathrm{PaCO}_{2}$ on the circulation are complex, involving local vasodilation, vasodilation mediated by the pulmonary inflation reflex, and vasoconstriction due to effects on central vasomotor centers and peripheral chemoreceptors. One might anticipate that some or all of these might differ between the fetus in utero and the newborn. Distribution of cardiac output was measured in unanesthetized fetal $(n=6)$ and newborn $(n=$ 7) sheep, using the radioactive microsphere technique. $\mathrm{PaCO}_{2}$ rose from 44 to 70 (fetus) and 38 to 60 torr (newborn) with the addition of $\mathrm{CO}_{2}$ to room air. In the fetus, there were significant increases in central nervous system (CNS), diaphragm, and lung blood flows. No organ showed a significant decrease in flow. Local vasodilation by $\mathrm{CO}_{2}$ was the likely cause of the increased flow to CNS. The large increase in pulmonary blood flow was most likely due to the associated rise in fetal $\mathrm{PaO}_{2}(23$ to 28 torr) that accompanied respiratory acidosis and the presence of fetal breathing movements. The rise in diaphragmatic blood flow was likely the result of fetal breathing. In the newborn, CNS and diaphragm flows rose, but unlike the fetus, spleen and stomach flows decreased. These decreased flows in the hypercapnic newborn may have been due to stimulation of either central vasomotor centers or peripheral chemoreceptors.
\end{abstract}

\section{Abbreviations}

CNS, central nervous system

DAo, descending aorta

DA, ductus arteriosus

I, aortic isthmus

PA, pulmonary artery

$\dot{Q}$, blood flow

$C$, radioactive counts

Studies of the redistribution of cardiac output induced by hypoxia in fetal and adult animals $(1,4,10)$ have shown that cardiac, cerebral, and adrenal oxygen delivery is preserved at the expense of other organs. Redistribution is accomplished by a local effect of hypoxia which dilates cerebral and coronary vessels, while the chemoreceptor reflex produces vasoconstriction in skeletal muscle and splanchnic beds (16).

The circulatory effects of changes in $\mathrm{PaCO}_{2}$, on the other hand, have not been as carefully studied. In particular, there are no data comparing effects before and after birth. The response of cardiac output and its regional distribution to changes in $\mathrm{PaCO}_{2}$ has been looked at in an acute fetal preparation but blood flow was measured only in major arteries (3). Only recently has the regional blood flow response been described in quantitative detail in a conscious adult animal (21). These studies done on adult sheep have shown that the effect of $\mathrm{CO}_{2}$ on the circulation is nonlinear. Cardiac output is unchanged as $\mathrm{PaCO}_{2}$ increases from 36 to $58 \mathrm{~mm} \mathrm{Hg}$; however, a $35 \%$ increase occurs as $\mathrm{PaCO}_{2}$ is further increased to $75 \mathrm{~mm} \mathrm{Hg}$. Nonlinearity characterized some of the responses of regional blood flows as well. These variable responses are not surprising when one considers that regional blood flow in hypercapnia depends upon complex interactions of a number of factors including local vasodilation by $\mathrm{CO}_{2}(7,9$, $13,20,29)$, vasodilation mediated by the pulmonary inflation reflex $(12,32)$, vasoconstriction induced by a central effect of $\mathrm{CO}_{2}$ on vasomotor centers (15), and vasoconstriction induced by effects on peripheral chemoreceptors (27). Given the complicated nature of these interactions, one might anticipate considerable differences in the response to respiratory acidosis before and after birth. Therefore, in conjunction with studies on developmental differences in the response of the cerebral circulation to $\mathrm{CO}_{2}$ (30), we have studied the distribution of cardiac output in the fetal and neonatal lamb after the induction of acute respiratory acidosis.

\section{MATERIALS AND METHODS}

Preparation. Six fetal lambs (128-132 days of gestation with term at 145 days) and seven newborn lambs (age 3-10 days) were studied. All animals were of mixed breed. Time-dated ewes with singleton pregnancies were operated upon under halothane anesthesia. The uterus was exposed by a midline abdominal incision. The extremities of the fetus were exposed through uterine incisions. Polyvinyl chloride catheters $(0.034$-inch ID $\times$ 0.054-in OD; Martech Medical Products, Lansdale, PA) were placed into the fetal inferior vena cava (via a pedal vein), the abdominal aorta (via pedal artery), and the brachiocephalic artery (via an axillary artery). The position of the catheter in the brachiocephalic artery was standardized as previously described (30). Tygon tubing (1/16-in ID $\times 1 / 8$-in OD; Norton Plastics, Akron, $\mathrm{OH})$ was placed into the amniotic cavity. Uterine and abdominal incisions were then closed, and the catheters were exteriorized through the ewe's flank. All ewes were allowed $72 \mathrm{~h}$ to recover prior to study.

The lambs were operated upon under pentobarbital anesthesia. Polyvinyl chloride catheters (as above) were placed into the abdominal aorta (via femoral artery), and into the brachiocephalic artery and left ventricle (via an axillary artery). When the lambs awoke from anesthesia, they were returned to their mothers. They were studied $24 \mathrm{~h}$ later. At that time, all lambs were standing and feeding normally.

Measurements. Total cardiac output and individual organ flows were measured using the radioactive microsphere technique $(18,28)$. In each animal, flows were measured while the animal breathed room air, and again while breathing an increased inspired $\mathrm{CO}_{2}$ concentration. Radioactive microspheres (approximately $1.0-1.5 \times 10^{6}\left(15 \mu \mathrm{m}\right.$ in diameter) labeled with ${ }^{85} \mathrm{Sr}$, 
${ }^{95} \mathrm{Nb},{ }^{46} \mathrm{Sc}$, or ${ }^{141} \mathrm{Ce}(3 \mathrm{M}$, St. Paul, MN) were injected over 1.5 min from a continuously stirred mixture of approximately 300,000 microspheres/ml into the inferior vena cava of the fetus and left ventricle of the newborn lamb. Meanwhile, reference blood samples were withdrawn from the brachiocephalic artery and abdominal aorta at a rate of $1.30 \mathrm{ml} \cdot \mathrm{min}^{-1}$ with a pump (Harvard Apparatus, Dover, MA). Withdrawal began 2 min before microsphere injection and continued for $1 \mathrm{~min}$ after it was completed. Microsphere injections were not associated with changes in blood pressure and heart rate. Individual organ flows were calculated according to the following equation $\dot{Q}_{0}=\mathrm{cpm}_{0} /$ $\mathrm{cpm}_{r} \times \dot{Q}_{r}$ where $\dot{Q}_{0}$ is organ blood flow (ml. $100 \mathrm{~g}^{-1} \mathrm{~min}^{-1}$ ), $\mathrm{cpm}_{0}$ is cpm. $100 \mathrm{~g}^{-1}$ in the organ tissue sample, $\mathrm{cpm}_{r}$ is counts/ min in the reference blood sample, and $\dot{Q}_{r}$ is the withdrawal rate of the reference sample $\left(\mathrm{ml} \cdot \mathrm{min}^{-1}\right)$. The brachiocephalic artery reference sample was used to calculate flows to the heart, brain, and upper body carcass and skin. The abdominal aorta reference sample was used to calculate flows to the lungs (bronchial arterial flow in the lamb), diaphragm, liver, spleen, adrenals, kidneys, gastrointestinal tract, lower body carcass, skin, and placenta (in the fetus). Lung flow calculated from the reference artery microsphere technique can be falsely elevated if there is shunting of microspheres through the systemic circulation. During injections, blood was withdrawn from a sagittal sinus catheter which had been placed in each animal for measurement of cerebral venous oxygen content for a coincident study (30). Significant microsphere numbers were not detected in either the control or hypercarbic states.

The abdominal aorta catheter is not the ideal reference catheter to calculate pulmonary blood flow in the fetus. A right ventricular or, even better, a pulmonary artery catheter is more appropriate (17). However, the abdominal aorta catheter has a reproducible relationship to a pulmonary artery reference sample, and should be adequate to assess large changes in lung blood flow.

The descending aorta (DAo) is a mixture of blood from the pulmonary artery via the ductus arteriosus (DA) [82\% of DAo flow (2)] and from the aortic isthmus (I) [18\% of DAo flow (2)].

$$
\dot{Q} \mathrm{DAo}=\dot{Q} \mathrm{DA}+\dot{Q} \mathrm{I}
$$

where $\dot{Q}=$ flow $\left(\mathrm{ml} \cdot \mathrm{min}^{-1}\right)$. Then

$$
\dot{Q} \mathrm{DAo}(C \mathrm{DAo})=\dot{Q} \mathrm{DA}(C \mathrm{PA})+\dot{Q} \mathrm{I}(C \mathrm{I})
$$

where $C$ represents radioactive counts $\cdot \mathrm{ml}^{-1}$ in the same arterial streams and PA represents pulmonary artery.

In our study, the ratio between the brachiocephalic artery (representative of $C \mathrm{I}$ ) and the descending aorta microsphere concentrations were 1.2 and 1.03 in control and hypercapnia respectively. Therefore

$$
\begin{aligned}
& \dot{Q} \mathrm{DAo}(C \mathrm{DAo})=\dot{Q} \mathrm{DA}(C \mathrm{PA})+\dot{Q} \mathrm{I}(1.2 C \mathrm{DAo}) \\
& \dot{Q} \mathrm{DAo}(C \mathrm{DAo})=\dot{Q} \mathrm{DA}(C \mathrm{PA})+\dot{Q} \mathrm{I}(1.03 C \mathrm{DAo})
\end{aligned}
$$

Rearranging to solve for the ratio of $C \mathrm{PA} / C \mathrm{DAo}$ :

$$
\begin{aligned}
& C \mathrm{PA} / C \mathrm{DAo}=(\dot{Q} \mathrm{DAo}-1.2 \dot{Q} \mathrm{I}) / \dot{Q} \mathrm{DA} \\
& C \mathrm{PA} / C \mathrm{DAo}=(\dot{Q} \mathrm{DAo}-1.03 \dot{Q} \mathrm{I}) / \dot{Q} \mathrm{DA}
\end{aligned}
$$

One can then substitute known values (2) for the relative flows in the various vessels as percentages of fetal cardiac output: $\dot{Q} \mathrm{DAo}=66 \%, \dot{Q D A}=54 \%, \dot{Q} \mathrm{I}=12 \%$. Solving for CPA $/$ CDAo yields a ratio of 0.96 and 0.99 for control and hypercapnia, respectively. Thus, under these circumstances, $C D A o \simeq C P A$ for calculation of lung blood flow. This will always be true when the ratio of microsphere concentrations above and below the ductus is near 1 as it was in our experiment. At higher ratios, the error will depend on the proportion of DAo blood from the isthmus. At a $C I / C D A o$ of 1.2 , the CPA/CDAo would still be 0.89 , even in the unlikely event that the relative isthmus contribution doubled.

Cardiac output was determined by summing the total flows to the individual organs, carcass, and skin. The radioactivity in each sample was determined using a two-channel $\gamma$-counter (Tracor Analytic, Des Plaines, IL). The tissues were prepared as described by Peeters et al. (28) with the exception that we used a 2-cm sample height in the counting vials. Adequate mixing of microspheres was confirmed at the organ level by comparison of right and left cerebral hemispheres, right and left kidneys, and upper and lower body skin. At the reference sample level, mixing was confirmed by validation studies comparing multiple brachiocephalic artery and abdominal aorta catheters. We also were unable to demonstrate a difference between left atrial and left ventricular injections in the lamb. All reference blood samples and tissues contained greater than 400 microspheres (8).

Blood samples for $\mathrm{pH}$, arterial $\mathrm{CO}_{2}$ tension $\left(\mathrm{PaCO}_{2}\right)$, arterial $\mathrm{O}_{2}$ tension $\left(\mathrm{PaO}_{2}\right)$, and hematocrit were withdrawn anaerobically into heparinized Natelson glass pipettes from the brachiocephalic artery (lamb and fetuses) and abdominal aorta (fetuses). Oxygen contents were measured using the Lex- $\mathrm{O}_{2}-\mathrm{Con}-\mathrm{TL}$ (Lexington Instruments, Walthan, $\mathrm{MA}$ ). $\mathrm{PaO}_{2}, \mathrm{PaCO}_{2}$, and $\mathrm{pH}$ were measured at $39.5^{\circ} \mathrm{C}$ using the Radiometer BMS3 MK2 (Radiometer, Copenhagen). Blood pressure and heart rate were continuously monitored in the abdominal aorta (Gould Instruments, Oxnard, $\mathrm{CA}$ ). In the lamb, the blood pressure was referenced to the right atrium and in the fetus to the amniotic fluid pressure.

Experimental Protocol. On the day of the experiment, the ewes (fetal studies) and lambs had opaque plastic bags placed over their heads to control the inspired gas composition. The bag was filled with a constant flow of room air to which $\mathrm{CO}_{2}$ was added in varying percentage $(0-10 \%)$ to obtain the desired $\mathrm{PaCO}_{2}$ for $10 \mathrm{~min}$. Blood gases and oxygen contents were drawn before and after each microsphere injection. In both the fetuses and lambs, individual organ flows and total cardiac output were ascertained in the control and hypercarbic states. Comparisons between control and hypercarbic conditions in the fetus and the lamb for blood gases, oxygen contents, blood pressure, and heart rate were made using paired $t$ tests with a Bonferroni correction (33). The critical Bonferroni value $\left(t^{*}\right)$ at $P<0.05$ was 2.99 in fetuses and 2.93 in the lambs. Comparisons of individual organ flows and cardiac output between control and hypercarbia were also calculated with paired $t$ tests with a Bonferroni correction $\left(t^{*}\right.$ at $P$ $<0.05-3.20$ for fetuses, 3.19 for lambs.

\section{RESULTS}

Physiologic Measurements. Baseline and hypercarbic physiologic measurements are presented in Table 1 (fetuses) and Table 2 (lambs). In the fetus, increases in $\mathrm{PaCO}_{2}$ resulted in significant increases in $\mathrm{PaO}_{2}$ in both the brachiocephalic artery $\left(\alpha_{1}\right)$ and abdominal aorta $\left(\alpha_{2}\right)$ due to the rightward shift in both the maternal fetal oxyhemoglobin dissociation curves $(23,24)$. There were no changes in $\mathrm{CaO}_{2}$, blood pressure, or heart rate. In the lamb, increases in $\mathrm{PaCO}_{2}$ also resulted in a significant increase in systemic $\mathrm{PaO}_{2}$, probably caused by hyperventilation and expansion of atelectatic areas with improvement in ventilation perfusion relationship. $\mathrm{CaO}_{2}$, blood pressure, and heart rate were unchanged.

Total Cardiac Output. Total cardiac output was not significantly different $\left(426 \pm 33\right.$ and $410 \pm 33 \mathrm{ml} \cdot \mathrm{kg}^{-1} \mathrm{~min}^{-1}$; mean \pm SEM) during control and hypercarbic states in the lambs (Fig. 1). In the fetus, it rose in five of six animals, but this was not significantly different $\left(433 \pm 20\right.$ and $494 \pm 29 \mathrm{ml} \cdot \mathrm{kg}^{-1} \mathrm{~min}^{-1}$; mean \pm SEM)

Individual Organ Blood Flows. In the fetus, flows (ml. $100 \mathrm{~g}^{-1}$ $\min ^{-1}$ ) to cerebral cortex, cerebellum, and brainstem were significantly increased as previously reported (30). In addition, diaphragm and lung blood flows rose significantly (Table 3 ).

In the lamb, flows $\left(\mathrm{ml} \cdot 100 \mathrm{~g}^{-1} \mathrm{~min}^{-1}\right)$ to cerebral cortex, cerebellum, and brainstem were significantly increased once again as previously reported (30). As in the fetus, diaphragm flow increased significantly. Flows to spleen and stomach were sig- 
Table 1. Physiologic measurements: fetuses*

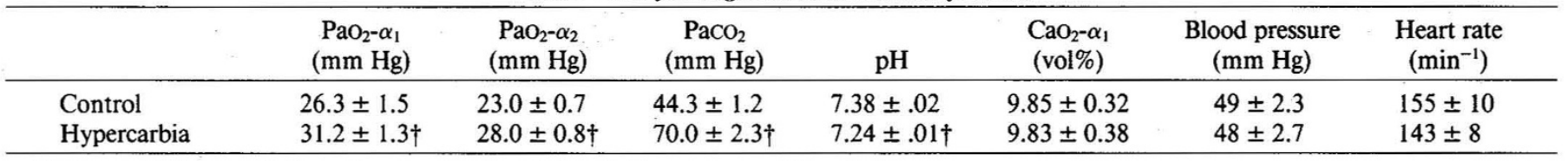

${ }^{*}$ Mean \pm SE for $n=6$ determinations; $\alpha_{1}$, brachiocephalic artery; $\alpha_{2}$, abdominal aorta.

$\dagger P<0.05$ using critical Bonferroni value of $t^{*}=2.99$.

Table 2. Physiologic measurements: lambs*

\begin{tabular}{|c|c|c|c|c|c|c|}
\hline & $\begin{array}{c}\mathrm{PaO}_{2} \\
(\mathrm{~mm} \mathrm{Hg})\end{array}$ & $\begin{array}{c}\mathrm{PaCO}_{2} \\
(\mathrm{~mm} \mathrm{Hg})\end{array}$ & $\mathrm{pH}$ & $\begin{array}{c}\mathrm{CaO}_{2} \\
\text { (vol\%) }\end{array}$ & $\begin{array}{c}\text { Blood } \\
\text { pressure } \\
(\mathrm{mm} \mathrm{Hg})\end{array}$ & $\begin{array}{c}\text { Heart rate } \\
\left(\min ^{-1}\right)\end{array}$ \\
\hline $\begin{array}{l}\text { Control } \\
\text { Hypercarbia }\end{array}$ & $\begin{aligned} 86.1 & \pm 4.0 \\
108.9 & \pm 4.5 \dagger\end{aligned}$ & $\begin{array}{l}37.9 \pm 1.7 \\
59.9 \pm 1.4 \dagger\end{array}$ & $\begin{array}{l}7.40 \pm .02 \\
7.27 \pm .02 \dagger\end{array}$ & $\begin{array}{l}17.4 \pm 1.0 \\
17.2 \pm 0.7\end{array}$ & $\begin{array}{l}84 \pm 3.1 \\
84 \pm 3.9\end{array}$ & $\begin{array}{l}179 \pm 9.5 \\
184 \pm 9.9\end{array}$ \\
\hline
\end{tabular}

* Mean \pm SE for $n=7$ determinations.

$\dagger P<0.05$ using critical Bonferroni value of $t^{*}=2.93$.
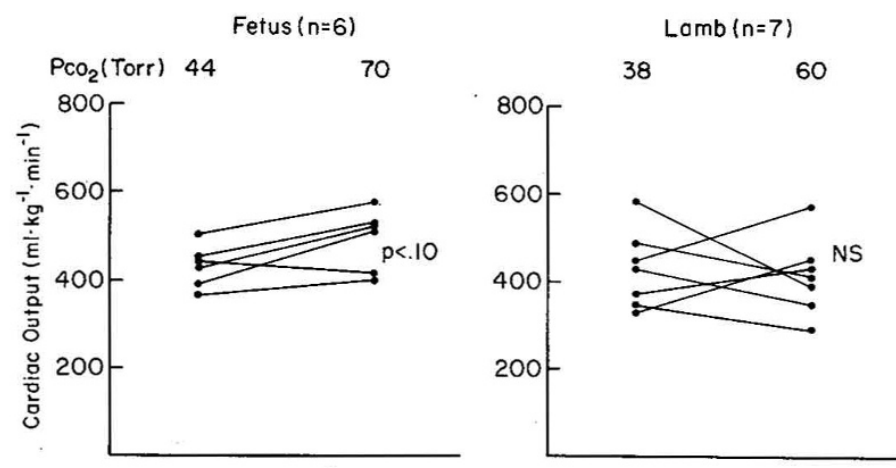

Fig. 1. Total cardiac output $\left(\mathrm{ml} \cdot \mathrm{kg}^{-1} \mathrm{~min}^{-1}\right)$ with hypercarbia in the fetal and neonatal lamb. Each pair of points connected by a line represents an individual animal.

Table 3. Organ blood flows: fetuses*

\begin{tabular}{lcc}
\hline & Control & Hypercarbia \\
\hline Cerebral cortex $\dagger$ & $113 \pm 13$ & $200 \pm 16$ \\
Cerebellum $\dagger$ & $134 \pm 15$ & $263 \pm 28$ \\
Brainstem $\dagger$ & $156 \pm 23$ & $415 \pm 46$ \\
Heart & $137 \pm 15$ & $154 \pm 14$ \\
Placenta & $182 \pm 14$ & $182 \pm 14$ \\
Carcass & $21 \pm 1$ & $21 \pm 2$ \\
Skin & $22 \pm 1$ & $20 \pm 2$ \\
Kidneys & $192 \pm 15$ & $192 \pm 13$ \\
Liver & $2 \pm 0.5$ & $3 \pm 0.4$ \\
Spleen & $392 \pm 43$ & $296 \pm 35$ \\
Stomach & $52 \pm 12$ & $49 \pm 8$ \\
Small bowel & $113 \pm 11$ & $146 \pm 13$ \\
Large bo vel & $47 \pm 3$ & $54 \pm 6$ \\
Adrenals & $271 \pm 42$ & $243 \pm 49$ \\
Diaphragm $\dagger$ & $18 \pm 5$ & $100 \pm 27$ \\
Lungs $\dagger$ & $112 \pm 35$ & $235 \pm 38$ \\
\hline
\end{tabular}

* Mean \pm SE for $n=6$ determinations ( $\left.\mathrm{ml} \cdot 100 \mathrm{~g}^{-1} \mathrm{~min}^{-1}\right)$.

$\dagger P<0.05$ using a critical Bonferroni value of $t^{*}=3.20$.

nificantly decreased (Table 4). There were no significant changes in flow to the remaining organs.

\section{DISCUSSION}

There are similarities but important differences as well in the distribution of cardiac output with hypercarbia among fetal, newborn, and adult sheep (Table 5). Complex interactions
Table 4. Organ blood flows: lambs*

\begin{tabular}{lcc}
\hline & Control & Hypercarbia \\
\hline Cerebral cortex $\dagger$ & $78 \pm 6$ & $196 \pm 14$ \\
Cerebellum $\dagger$ & $93 \pm 6$ & $229 \pm 22$ \\
Brainstem $\dagger$ & $74 \pm 6$ & $283 \pm 24$ \\
Heart & $170 \pm 14$ & $208 \pm 16$ \\
Carcass & $25 \pm 3$ & $25 \pm 2$ \\
Skin & $21 \pm 2$ & $19 \pm 2$ \\
Kidneys & $537 \pm 65$ & $400 \pm 20$ \\
Liver & $17 \pm 8$ & $12 \pm 5$ \\
Spleen $\dagger$ & $561 \pm 50$ & $346 \pm 47$ \\
Stomach $\dagger$ & $167 \pm 42$ & $107 \pm 23$ \\
Small bowel & $332 \pm 31$ & $273 \pm 27$ \\
Large bowel & $143 \pm 20$ & $126 \pm 9$ \\
Adrenals & $335 \pm 49$ & $362 \pm 54$ \\
Diaphragm $\dagger$ & $27 \pm 2$ & $180 \pm 46$ \\
Lungs (bronchial) & $73 \pm 21$ & $73 \pm 26$ \\
\hline
\end{tabular}

* Mean \pm SE for $n=7$ determinations ( $\left.\mathrm{ml} \cdot 100 \mathrm{~g}^{-1} \mathrm{~min}^{-1}\right)$.

$\dagger P<0.05$ using a critical Bonferroni value of $t^{*}=3.19$.

Table 5. Developmental comparison of circulatory changes with hypercarbia

\begin{tabular}{lccc}
\hline & Fetus & Lamb & Adult* \\
\hline $\mathrm{PaCO}_{2}$ (mm Hg) $\dagger$ & 26 & 22 & 22 \\
Cardiac output $\left(\mathrm{ml} \cdot \mathrm{kg}^{-1} \mathrm{~min}^{-1}\right)$ & $\rightarrow$ & $\rightarrow$ & $\rightarrow$ \\
Organ flows (ml. $\left.100 \mathrm{~g}^{-1} \mathrm{~min}^{-1}\right)$ & & & \\
CNS & $\uparrow$ & $\uparrow$ & $\uparrow$ \\
$\quad$ Diaphragm & $\uparrow$ & $\uparrow$ & $\uparrow$ \\
Heart & $\rightarrow$ & $\rightarrow$ & $\rightarrow$ \\
Stomach & $\rightarrow$ & $\downarrow$ & Not measured \\
Spleen & $\rightarrow$ & $\downarrow$ & $\rightarrow$ \\
Pulmonary & $\uparrow$ & Not measured Not measured \\
\hline * Matalon et al. (21). & & & \\
$\dagger$ Ranges studied: fetus $(44-70 \mathrm{~mm} \mathrm{Hg})$, lamb (38-60 mm Hg), adult
\end{tabular}
$(36-58 \mathrm{~mm} \mathrm{Hg})$.

among a number of factors that may be influenced by development may be involved in the circulatory changes during respiratory acidosis. Individual vessels may dilate because of the local effects of $\mathrm{CO}_{2}$. This has been shown experimentally in a variety of vascular beds including cerebral (20), mesenteric (7), coronary (9), renal (13), and limb $(13,29)$. On the other hand, hypercapnia provokes peripheral vasoconstriction via an effect both on the central nervous system (15) and peripheral chemoreceptors (27). Elevations in $\mathrm{PaCO}_{2}$ also increase respiration and stimulate the 
pulmonary stretch receptors which induce skin, muscle, renal, and splanchnic vasodilation $(12,32)$. Finally, organ blood flow response to $\mathrm{PaCO}_{2}$ may be influenced by different functional stages in organ develoment.

These experiments were only descriptive. With that in mind, the ensuing discussion will consider possible explanations of the circulatory responses to $\mathrm{CO}_{2}$ we observed. Specific studies designed to answer these questions will be necessary in order to investigate these possibilities.

In the lamb, we found significant redistribution of cardiac output. There were increases in flow to all CNS structures thought to be secondary to local vasodilation by $\mathrm{CO}_{2}(20)$, and an increase in diaphragm flow secondary to the stimulation of breathing (19). The increases in CNS and diaphragm flows were qualitatively similar to those in our fetuses and Matalon's adults (21). These increases in flow were accompanied by significant decreases in splenic and stomach blood flows, as well as consistent (seven of seven animals) but not statistically significant decreases in small bowel and renal blood flows, perhaps due to the predominance of vasoconstrictive effects of $\mathrm{CO}_{2}$ mediated by central vasomotor centers (15) and/or peripheral chemoreceptors (27). These decreases were not observed in the fetus, which could be due to immaturity of the fetal autonomic nervous system ( 5 , $14,34)$. However, at comparable increases in $\mathrm{CO}_{2}$ in the adult sheep, renal, intestinal, and splenic flows were unchanged as well (21). Explanations unrelated to the autonomic nervous system may therefore be important. Baseline splenic and intestinal flows are considerably higher in the lamb than in the adult or fetus. This relative state of vasoconstriction in the fetus and adult may make these beds less responsive to chemoreceptor-induced vasoconstriction with hypercarbia than is the case in the lamb. Secondly, there are functional intestinal differences: the intestines are not functioning as a digestive organ in the fetus, the lamb is on a purely milk diet, and the adult is a ruminant. The importance of these differences on the response of their respective blood flows to hypercarbia needs to be investigated.

The most striking finding in the fetus was a large increase in pulmonary blood flow. This increase occurred in all six fetuses studied and averaged $110 \%$ of control (Fig. 2). There are several potential explanations for this finding including: local effects of $\mathrm{PaCO}_{2}$ or $\mathrm{PaO}_{2}$ on the pulmonary vasculature, or the effects of the induction of fetal breathing on the pulmonary vasculature. Data from adults (21) and neonates (31) show no change or increased pulmonary vascular resistance during respiratory or metabolic acidosis. Studies in fetal sheep have failed to identify an independent effect of $\mathrm{PaCO}_{2}$ on pulmonary blood flow (25). However, the increase in fetal pulmonary flow could have been due to the rise in fetal $\mathrm{PaO}_{2}$ that accompanied respiratory acidosis. Respiratory acidosis produces a rightward shift in the maternal

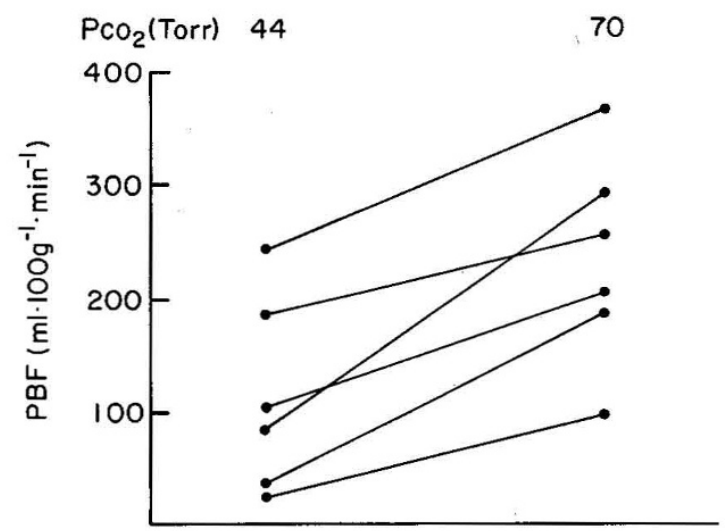

Fig. 2. Pulmonary blood flow $\left(P B F ; \mathrm{ml} \cdot 100 \mathrm{~g}^{-1} \mathrm{~min}^{-1}\right)$ with hypercarbia in the fetal lamb. Each pair of points connected by a line represents an individual animal. oxyhemoglobin dissociation curve that would raise uterine vein and thus umbilical vein $\mathrm{PO}_{2}$ (23). A similar shift in the fetal dissociation curve will raise umbilical vein $\mathrm{Po}_{2}$ by a more complex mechanism discussed in detail by Meschia et al. (24). As a result, fetal $\mathrm{PaO}_{2}$ in the abdominal aorta increased from 23 to 28 $\mathrm{mm} \mathrm{Hg}$. Changes in $\mathrm{PaO}_{2}$ over this range have been shown to cause marked increases in pulmonary blood flow (22). One other factor also involved in the increase in pulmonary blood flow is suggested by the increase in diaphragm flow. Hypercapnia induces fetal breathing (6) and consequently an increase in blood flow to the diaphragm (26). Fetal breathing movements may also independently increase pulmonary blood flow (25).

The individual effects of the various influences on the fetal vascular response to hypercapnia are difficult to dissect. The "normal" fetal $\mathrm{PaO}_{2}$ is quite low by postnatal standards. In adults, the combination of hypoxia and hypercapnia enhances peripheral chemoreceptor activity (11). However, unlike with the lamb, we have no evidence of chemoreceptor-induced vasoconstriction even in beds likely to show a chemoreflex-mediated decrease in flow (spleen and stomach). There are several possible explanations. The central vasomotor center and peripheral chemoreceptors might not respond to the degree of hypercapnia induced in our fetal studies or the autonomic effector system might not be fully developed. There is evidence from fetal lamb studies that carotid, but not aortic chemoreceptor sensitivity is suppressed until the time of birth $(5,14)$, and that fetal cardiovascular response to autonomic agonists increases during intrauterine and postnatal develoment (34). It is also possible that vasoconstrictive effects are present but counterbalanced by $\mathrm{CO}_{2}$-induced local vasodilation.

\section{REFERENCES AND NOTES}

1. Adachi H, Strauss HW, Ochi H, Wagner HN Jr 1976 The effect of hypoxia on the regional distribution of cardiac output in the dog. Circ Res 39:314

2. Anderson DF, Bissonnette JM, Faber JJ, Thornburg KL 1981 Central shunt flows and pressures in the mature fetal lamb. Am J Physiol [Heart Circ Physiol 10] 241:H60

3. Assali NS, Holm LW, Sehgal N 1962 Hemodynamic changes in fetal lamb in utero in response to asphyxia, hypoxia and hypercapnia. Circ Res 11:423

4. Behrman RE, Lees MH, Peterson EN, deLannoy CW, Seeds AE 1970 Distribution of the circulation in the normal and asphyxiated fetal primate. Am J Obstet Gynecol 108:956

5. Biscoe TJ, Purves MJ, Sampson SR 1969 Types of nervous activity which may be recorded from the carotid sinus nerve in the sheep foetus. J Physiol 202:1

6. Bowes G, Wilkinson MH, Dowling M, Ritchie BC, Brodecky V, Maloney JE 1981 Hypercapnic stimulation of respiratory activity in unanesthetized fetal sheep in utero. J Appl Physiol Respir Environ Exercise Physiol 50:701

7. Brickner EW, Dowds EG, Willitts B, Selkurt EE 1956 Mesenteric blood flow as influenced by progressive hypercapnia. Am J Physiol 184:275

8. Buckberg GD, Luck JC, Payne B, Hoffman JIE, Archie J; Fixler DE 1971 Some sources of error in measuring regional blood flow with radioactive microspheres. J Appl Physiol 31:598

9. Case RB, Greenberg H 1976 The response of canine coronary vascular resistance to local alterations in coronary arterial $\mathrm{PCO}_{2}$. Circ Res 39:558

10. Cohn HE, Sacks EJ, Heymann MA, Rudolph AM 1974 Cardiovascular responses to hypoxemia and acidemia in fetal lambs. Am J Obstet Gynecol 120:817

11. Daly M deB, Hazzledine JL, Howe A 1965 Reflex respiratory and peripheral vascular responses to stimulation of the isolated perfused aortic arch chemoreceptors of the dog. J Physiol 177:300

12. Daly M deB, Robinson BH 1968 An analysis of the reflex systemic vasodilator response elicited by lung inflation in the dog. J Physiol 195:387

13. Daugherty RM Jr, Scott JB, Dabney JM, Haddy FJ 1967 Local effects of $\mathrm{O}_{2}$ and $\mathrm{CO}_{2}$ on limb, renal and coronary vascular resistances. Am J Physiol 213:1102

14. Dawes GS, Duncan SLB, Lewis BV, Merlet CL, Owen-Thomas JB, Reeves JT 1969 Hypoxaemia and aortic chemoreceptor function in foetal lambs. J Physiol 201:105

15. Downing SE, Mitchell JH, Wallace AG 1963 Cardiovascular responses to ischemia, hypoxia, and hypercapnia of the central nervous system. Am J Physiol 204:881

16. Heistad DD, Abboud FM 1980 Circulatory adjustments to hypoxia. Circulation 61:463

17. Heymann MA, Creasy RK, Rudolph AM 1973 Quantitation of blood flow patterns in the foetal lamb in utero. In: Comline KS, Cross KW, Dawes GS, Nathanielsz PW (eds) Foetal and Neonatal Physiology. Cambridge University Press, Cambridge, UK, pp 129-135

18. Heymann MA, Payne BD, Hoffman JIE, Rudolph AM 1977 Blood flow measurements with radionuclide-labeled particles. Prog Cardiovasc Dis 20:55 
19. Kendrich JE, DeHaan SJ, Parke JD 1981 Regulation of blood flow to respiratory muscles during hypoxia and hypercapnia. Proc Soc Exp Biol Med 166:157

20. Kontos HA, Wei EP, Raper AJ, Patterson JL Jr 1977 Local mechanism of $\mathrm{CO}_{2}$ action on cat pial arterioles. Stroke 8:226

21. Matalon S, Nesarajah MS, Krasney JA, Farhi LE 1983 Effects of acute hypercapnia on the central and peripheral circulation of conscious sheep. $J$ Appl Physiol Respir Environ Exercise Physiol 54:803

22. Melmed H, Molteni RA, Jones MD Jr, Sheldon RE, Makowski EL, Meschia G 1980 Effect of $\mathrm{PO}_{2}$ on fetal pulmonary blood flow. Abstract Presented to the Society for Gynecologic Investigation, Atlanta, GA,

23. Meschia G 1976 Physiology of transplacental diffusion. In: Wynn RM (ed) Obstetrics and Gynecology Annual. Appleton-Century-Crofts, Norwalk, CT, pp 21-38

24. Meschia G, Battaglia FC, Makowski EL, Droegemueller W 1969 Effects of varying umbilical blood $\mathrm{O}_{2}$ affinity on umbilical vein $\mathrm{PO}_{2}$. J Appl Physiol $26: 410$

25. Molteni RA, Jones MD, Jr, Simmons MA 1980 The effect of breathing on pulmonary blood flow in the sheep fetus. Pediatr Res 14:648

26. Molteni RA, Melmed MH, Sheldon RE, Jones MD Jr, Meschia G 1980 Induction of fetal breathing by metabolic acidemia and its effect on blood flow to the respiratory muscles. Am J Obstet Gynecol 136:609

27. Parker PE, Dabney JM, Scott JB, Haddy FJ 1975 Reflex vascular responses in kidney, ileum, and forelimb to carotid body stimulation. Am J Physiol 228:46

28. Peeters LLH, Sheldon RE, Jones MD Jr, Makowski EL, Meschia G 1979
Blood flow to fetal organs as a function of arterial oxygen content. Am J Obstet Gynecol 135:637

29. Radawski D, Dabney JM, Daugherty RM Jr, Haddy FJ, Scott JB 1972 Local effects of $\mathrm{CO}_{2}$ on vascular resistances and weight of the dog forelimb. Am J Physiol 222:439

30. Rosenberg AA, Jones MD Jr, Traystman RJ, Simmons MA, Molteni RA 1982 Response of cerebral blood flow to changes in $\mathrm{PCO}_{2}$ on fetal, newborn and adult sheep. Am J Physiol [Heart Circ Physiol 11] 242:H862

31. Rudolph AM, Yuan S 1966 Response of the pulmonary vasculature to hypoxia and $\mathrm{H}^{+}$ion concentration changes. J Clin Invest 45:399

32. Rutherford JD, Vatner SP 1978 Integrated carotid chemorecepter and pulmonary inflation reflex control of peripheral vasoactivity in conscious dogs. Circ Res 43:200

33. Wallenstein S, Zucker CL, Fleiss JL 1980 Some statistical methods useful in circulation research. Circ Res 47:1

34. Woods JR Jr, Dandavino A, Murayama K, Brinkman CR III, Assali NS 1977 Autonomic control of cardiovascular functions during neonatal development and in adult sheep. Circ Res 40:401

35. Correspondence should be addressed to Adam A. Rosenberg, M.D., Division of Perinatal Medicine, CMSC 210, The Johns Hopkins Hospital, 600 North Wolfe Street, Baltimore, Md 21205.

36. The work was supported in part by The Hospital for Consumptives of Maryland (Eudowood) and by National Institutes of Health Research Grant HD13830.

37. Received for publication November 29, 1983.

\title{
Diabetes in Pregnancy: Decreased Placental Blood Flow and Disturbed Fetal Development in the Rat
}

\author{
ULF J. ERIKSSON ${ }^{(37)}$ AND LEIF JANSSON \\ Department of Medical Cell Biology, University of Uppsala, Uppsala, Sweden
}

\begin{abstract}
Summary
Placental blood flow was measured with the aid of radioactive microspheres, in normal (N) and manifest diabetic (MD) rats, and related to fetal body growth and incidence of congenital malformations. The total blood flow in the placentae of the MD rats was decreased to about one-half of the normal flow on gestational days 20 and 22 . The placentae of the MD offspring were enlarged, whereas the fetuses in this group were smaller than normal. Thus, the placental blood flow per placental weight was drastically decreased in the MD fetuses on both days 20 and 22. In contrast, the placental blood flow per fetal weight was not different in the $\mathbf{N}$ and MD groups on gestational day 20 whereas it was decreased in the MD offspring on gestational day 22 . Placental blood flow in the malformed fetuses of the MD group did not differ significantly from that in the nonmalformed MD fetuses.
\end{abstract}

\section{Abbreviations}

$\mathbf{N}$, normal control rat (nondiabetic)

N20 or N22, normal pregnant rat on gestational day 20 or 22

MD, manifest diabetic rat (serum glucose level exceeding 20 $\mathrm{mmol} / \mathrm{liter}$ )

MD20 or MD22, pregnant manifest diabetic rat on gestational day 20 or 22
The etiology of altered fetal development defined as increased/ decreased fetal weight, malformations, and an increased number of resorptions in the diabetic pregnancy is at present not clear (23). Disturbances in the transfer of nutrients from mother to fetus, reflecting altered placental function, may be of importance for the decreased somatic growth rate $(17,18)$. Besides, the magnitude of the placental blood flow determines the amount of nutrients available for transfer to the fetus (27). Therefore, placental blood flow may be relevant to fetal growth retardation (28). Decreased placental blood supply has been accomplished experimentally in rats subjected to uterine artery ligation (21) and maternal dietary restriction (29). The offspring of these rats show decreased fetal weights and increased number of intrauterine resorptions.

Although a number of estimations of placental blood flow in rodents have been reported $(1,2,5,7,15,16,27,29,34)$, no studies of placental blood flow in diabetic rat pregnancy seem to have been published. There are, however, reports of altered placental morphology (26) and indirect evidences of changed vascular function in diabetic rat placenta (4) as well as decreased transfer of aminoisobutyric acid to fetuses of diabetic guinea pigs (30). Also, reduced uteroplacental blood flow as determined with placental scintigraphy has recently been demonstrated in human diabetic pregnancy (19).

The aim of the present study was to examine the relation 